\title{
Autonomia e justiça no debate sobre aborto: implicações teóricas e políticas
}

Autonomy and justice in the debate about abortion: theoretical and political implications

O debate sobre aborto se define em disputas concretas em torno do direito ao aborto ${ }^{1}$. Abordagens teóricas e posições políticas são construídas diante de um fato, a prática do aborto voluntário, e diante de valores políticos que ganharam novas configurações e tiveram sua relevância ampliada nas sociedades contemporâneas relativamente a outros períodos históricos. Entre esses valores, destaco a autonomia individual, com foco específico na autonomia das mulheres, e a laicidade do Estado. Ainda que se observe apenas o mundo ocidental, as ações do Estado nos domínios da reprodução e da sexualidade, assim como os limites entre a laicidade do Estado e a atuação política das igrejas, assumiram diferentes padrões ao longo do tempo e em diferentes sociedades, mobilizando ou confrontando de maneiras distintas os valores mencionados.

O caráter "universal" da prática do aborto, isto é, o fato de que seja reconhecida como possibilidade em diferentes sociedades (Boltanski, 2004, p. 28, a partir da pesquisa de George Devereux, 1955) e que existam indícios e

\footnotetext{
É professora do Instituto de Ciência Política da Universidade de Brasília (Brasília, DF).E-mail: flaviabiroli@ gmail.com.

A discussão apresentada neste artigo integra a pesquisa"Direito ao aborto e sentidos da maternidade: atores e posições em disputa no Brasil contemporâneo", financiada pelo edital MCTI/CNPq/SPM-PR/ MDA 32/2012, e a pesquisa "Desigualdades e preferências: a tensão entre o valor da autonomia individual e a crítica à opressão na teoria política contemporânea" (CNPq, bolsa PQ). Agradeço às colegas e alunas do Grupo de Pesquisas sobre Democracia e Desigualdades (http://www.demode.unb.br) por discussões que colaboraram muito para as reflexões que aqui apresento.
} 
informações que permitem afirmar que seja uma prática frequente mesmo nas sociedades em que não é legalizada, convive com diferentes graus de tolerância e de reprovação. Segundo a Organização Mundial de Saúde, em estimativas divulgadas em 2012, 22 milhões de mulheres em todo o mundo se submetem, anualmente, a abortos inseguros. A prática do aborto se caracterizaria, assim, ainda hoje e após mudanças na legislação em vários países, por ocupar um lugar entre o que é da ordem da transgressão e o que é da ordem do aceitável. É isso que explicaria seu caráter ao mesmo tempo generalizado e de conhecimento comum e as restrições na sua representação, isto é, os interditos e limites para que seja tópico de conversações e ganhe lugar nos discursos “oficiais" (Boltanski, 2004, p. 38).

No debate na Ciência Política, sua tematização encontra barreiras adicionais pelo fato de que a discussão sobre o direito ao aborto se produz na encruzilhada entre posições políticas, valores morais e análise academicamente referenciada. As teorias feministas que privilegiaram o tema, por sua vez, além de serem marginais no campo, confrontam amplamente vários dos seus cânones ao se recusarem a operar com uma noção abstrata do indivíduo e das suas escolhas e com a noção de imparcialidade como valor para a política e para a produção acadêmica.

Pela legislação brasileira atual, aborto é crime. As exceções são os casos em que há risco de vida para as mulheres gestantes, gravidez resultante de estupro e, desde 2012, os casos de má-formação fetal diagnosticada como anencefalia. A ilegalidade, no entanto, reflete pouco a realidade social das mulheres diante do aborto. A distância entre as normas restritivas e a realidade social das mulheres permite equiparar a proibição do aborto hoje à restrição ao divórcio no Brasil antes de $1977^{2}$. Estima-se que mais de uma em cada cinco mulheres brasileiras fez pelo menos um aborto (Diniz \& Medeiros, 2010, p. 964). É importante ter em mente que a prática do aborto não é reduzida pela criminalização, mas brutalizada, e tanto mais perigosa para as mulheres quanto maiores são os esforços para fazer cumprir a lei (Boltanski, 2004, p. 124). A clandestinidade corresponde à realização do aborto em condições precárias e, novamente, tanto mais precárias quanto mais efetivas são as políticas de repressão, resultando em um número elevado de complicações e de mortes ${ }^{3}$.

a Faço essa afirmação a partir das observações desses dois contextos feitas por Mala Htun (2003).

Segundo dados oficiais do Ministério da Saúde de 2006, o aborto clandestino é a causa de 11,4\% das 
A prática do aborto, que tomo aqui, assim, como um fato independentemente da sua legitimidade e legalidade, passou a ser criminalizada, no Ocidente, a partir de meados do século XIX. Cerca de um século depois, em meados do século XX, a criminalização seria revogada em muitos países ocidentais, sobretudo no hemisfério norte, e reduzida ou atenuada em países nos quais ainda existe. Estiveram em curso, nesse processo, transformações na atuação do Estado no âmbito do que Michel Foucault (1999) denominou "biopolítica", isto é, nos arranjos que permitiram justificar e efetivar o controle do Estado sobre as populações. Ao longo do século XIX, a demografia e as ciências biológicas, as chamadas ciências da vida, passariam a convergir na definição da reprodução como questão de caráter político, em um sentido bastante distinto daquele que seria, posteriormente, reivindicado pelos movimentos feministas. Há uma correlação, permanente mas variável em seus sentidos, entre o controle da sexualidade das mulheres, os discursos sociais hegemônicos sobre a reprodução e a questão do direito ao aborto.

É importante ter clareza de que a questão não é a realização do aborto, mas quem decide, e em que circunstâncias, sobre a sua realização. Perspectivas eugênicas estiveram na base de propostas de flexibilização nas leis que criminalizavam o aborto na América Latina no início do século XX (Htun, 2003, p. 146). Entre as mulheres pobres, negras e indígenas da América, o racismo e o controle populacional fundamentaram políticas de controle que promoveram a esterilização - realizada em grande escala em meados do século XX (Schoen, 2005) - adotadas como políticas de Estado até muito recentemente, como no Peru de Alberto Fujimori, já nos anos 1990 (Tamayo, 1999). Eugenia, racismo e a busca do controle social da pobreza fundamentaram, assim, políticas que fizeram do corpo das mulheres objeto de intervenções sancionadas. Classe e raça se impõem como variáveis nesse caso, expondo o fato de que as experiências das mulheres variam segundo sua posição social também no que diz respeito à política reprodutiva. Não é apenas o aborto clandestino que deixa marcas distintas e consequências

mortes maternas e 17\% do total de mortes por razões obstétricas. Esse número é menor do que o que foi apontado por estatísticas dos anos 1990, provavelmente pela difusão do uso de substâncias como o misoprostol em vez de métodos perfurativos ou cáusticos (Ministério da Saúde, 2009). Relatos, sobretudo de mulheres das camadas mais pobres da população, indicam que o acesso a substâncias abortivas na clandestinidade continua a se dar de forma não apenas precária, mas que compromete a saúde das mulheres e também a das crianças nos casos em que a tentativa de aborto não tem sucesso (vale conferir os relatos apresentados por Motta, 2012). 
em geral mais graves entre as mulheres pobres (Ministério da Saúde, 2009): historicamente, os limites para a autonomia relativa à reprodução não têm atingido todas as mulheres igualmente. Vinculadas ao racismo e ao controle populacional, as políticas de esterilização levadas a cabo em várias partes do mundo em meados do século XX são um caso representativo, em que as mulheres pobres foram, ao mesmo tempo, alvo de esterilizações involuntárias e tiveram o acesso à esterilização voluntária, aborto seguro e anticonceptivos negado de maneira desproporcional em relação às mulheres brancas (Schoen, 2005, p. 138).

Em uma perspectiva distinta, na qual o controle do Estado seria buscado e legitimado em nome de preceitos religiosos, a Igreja Católica ampliou o peso das questões sexuais e reprodutivas na sua agenda ao longo do século XX, em especial após 1978, quando Karol Wojtyla (João Paulo II) se tornou papa. A oposição ao controle da natalidade e ao uso de contraceptivos, como a camisinha e a pílula anticoncepcional, apareceria aliada a uma oposição sistemática ao aborto voluntário. Essa agenda foi e é ainda mobilizada para a valorização de uma concepção convencional da família e de uma ordem sexual conservadora, baseada no casamento e na suposta complementaridade entre homens e mulheres. A posição da mulher é tomada como seu papel nessas relações, com sua individualidade subsumida a seu papel como mãe. A abstração que permite considerar os indivíduos como cidadãos, igualmente, de modo que independeria de sua posição nas relações sociais é, assim, colocada em xeque em regimes que, em outras dimensões, aderem a normas e valores liberais. Dito de outro modo, a suspensão da condição das mulheres como indivíduo é corroborada jurídica e politicamente nas sociedades nas quais a criminalização do direito ao aborto é feita com base em preceitos religiosos.

As políticas de caráter eugenista, mencionadas anteriormente, foram questionadas pela Igreja Católica e por outras religiões organizadas, mas não por atentarem contra a autonomia individual das mulheres. É interessante observar que sua condenação faz parte do entendimento, mobilizado contrariamente ao direito ao aborto, de que as mulheres não interromperiam uma gravidez em seu próprio interesse. Mas isso não significa que a vocalização dos seus interesses pelas próprias mulheres ganhe o centro das considerações. O mesmo ocorre quando se mobiliza a crítica ao "individualismo contemporâneo" como algo que fere os interesses das mulheres. Um documento 
da Associação Nacional Pró-Vida e Pró-Família, organização antiaborto fundada em 1993 e atuante no Brasil, exemplifica esse tipo de posição. Ele relaciona o individualismo consumista contemporâneo, a desvalorização da vida e o entendimento de que o aborto corresponde à eliminação dos "indesejáveis", isto é, "todas as pessoas que não se enquadram no indivíduo ideal criado pela sociedade atual” (Santos, p. 2, s/d). Os desvios do individualismo contemporâneo, que confundiria pessoas com consumidores, produziriam simultaneamente a desvalorização dos indivíduos adultos e a desvalorização dos fetos: a ideia principal, mobilizada constantemente pelos movimentos contrários ao direito ao aborto, é de que em um mundo materialista e individualista a vida se tornaria descartável.

Em nenhum desses registros, e aqui integro o da eugenia ao da oposição religiosa à contracepção e ao aborto, as mulheres são tomadas como indivíduos que têm perspectivas e interesses singulares e distintos daqueles que se atribui ao feto - o interesse na continuidade da própria vida. A recusa à autonomia das mulheres como valor corresponde à recusa a tomá-las como fonte legítima para a produção das interpretações sobre seus próprios interesses e sobre o sentido da vida. Embora não seja possível tomar as diferentes denominações religiosas que têm presença no debate público no Brasil hoje como se fossem um bloco na sua atuação relativa às políticas reprodutivas e em suas concepções das relações de gênero, elas convergem na defesa da família (Machado, 2013), assumindo posições opostas à individualização das mulheres, isto é, a sua definição como sujeito de direitos e de interesses.

É, distintamente, na atuação dos movimentos feministas que a agenda da reprodução e da sexualidade seria politizada e associada à autonomia e cidadania das mulheres. Em um sentido genérico, que será matizado e especificado mais adiante, a autonomia que assim se define corresponde ao controle das mulheres sobre seu corpo e sobre sua capacidade reprodutiva. Seu terreno é delimitado em oposição, e por contraste, (a) à regulação e intervenção por parte do Estado e dos seus agentes, (b) ao controle por parte das famílias, na forma da autoridade dos pais, dos maridos, mas também de mulheres ${ }^{4}$, (c) às formas de regulação baseadas em crenças religiosas.

Refiro-me aqui ao papel das mulheres, sobretudo das mulheres mais velhas, na reprodução dos constrangimentos e controles sobre o corpo de outras mulheres. Elas podem ser agentes importantes na mobilização, no cotidiano, dos valores que tiveram e continuam a ter centralidade em uma ordem moral na qual o fortalecimento da autonomia individual - sobretudo a das mulheres jovens - aparece como um fator disruptivo da ordem familiar e da ordem social em sentido mais amplo. 
A afirmação da autonomia das mulheres para decidir sobre a interrupção da gravidez é, assim, algo que toca em questões que não se restringem ao aborto, mas ao funcionamento da democracia, aos espaços e formas da regulação do Estado, às hierarquias e formas toleráveis da dominação, aos direitos individuais e à relação entre todas essas questões e o princípio da laicidade do Estado. Ao mesmo tempo, ao expor os imperativos que estão na base de representações sociais convencionais da sexualidade e da reprodução, a defesa do direito ao aborto coloca em questão pilares fundamentais da ordem de gênero. Pelo menos dois merecem ser destacados: a interface entre o controle da sexualidade das mulheres e a violência contra as mulheres, que se intensifica na tolerância ampliada à violência contra mulheres de comportamento moral "duvidoso" (Collouris, 2010) e o dispositivo da maternidade, que conjuga incitações, constrangimentos e restrições ao comportamento das mulheres na fusão entre o feminino e o maternal (Badinter, 1985 [1980]; Biroli, 2014). Esse dispositivo me parece central para que a preservação e a proteção das próprias mulheres sejam enunciadas como justificativa para posições contrárias ao direito ao aborto: seria preservada sua condição de mãe, sem a qual sua individualidade não se sustentaria como valor. Quando seu valor é restrito a um papel, definindo-as por ele, as mulheres se tornam menos do que cidadãs. Essa identidade suspende, também, a diversidade existente entre as próprias mulheres, que podem desejar ser mães ou não, ser heterossexuais ou não, identificar-se em graus distintos ao longo da sua vida com a maternidade como projeto.

A autonomia das mulheres está, assim, no centro das disputas relativas ao aborto. Os arranjos atuais - o conjunto das normas, das representações e das justificações - que organizam e que coíbem a prática do aborto nas nossas sociedades são, sempre, arranjos que incidem sobre seu exercício.

Nesta primeira seção expus, assim, algumas das razões pelas quais a autonomia das mulheres é uma questão incontornável no debate sobre aborto. Nas próximas seções, dou sequência à discussão mostrando que a relação autonomia-aborto toma formas distintas no debate teórico, mobilizando o conceito de autonomia de maneiras variáveis e a partir de pontos de partida distintos. A segunda seção apresenta, brevemente, as linhas de força na argumentação liberal que dá sustentação ao direito ao aborto. Em seguida, a terceira seção mostra como elaborações feministas sobre o direito ao aborto apresentam variações, e mesmo dimensões do problema, que ampliam ou 
tensionam os enquadramentos liberais. Argumento que as teorias feministas que extrapolam o liberalismo trazem contribuições ímpares ao debate sobre autonomia (e não apenas na sua relação com a temática do aborto) porque têm como ponto de partida as relações de gênero, dando centralidade às experiências das mulheres. $\mathrm{O}$ fato de que as mulheres sejam tomadas como fontes legítimas para a atribuição de significado ao aborto impõe uma série de deslocamentos que, devedores de articulações produtivas entre o ativismo político feminista e a análise acadêmica, redefinem o escopo da própria teoria em sua crítica às concepções abstratas da individualidade, avançando na contextualização dos argumentos teóricos e trazendo novos problemas e ângulos para a crítica democrática ${ }^{5}$. Por fim, a quarta seção apresenta conclusões nas quais equaciono, brevemente, o problema do sentido da vida à relação entre aborto, autonomia e cidadania.

\section{Direitos individuais e o direito a decidir sobre o próprio corpo}

A decisão individual sobre recorrer ou não a um aborto pode ser definida como uma decisão de caráter moral. Isso significa, basicamente, que há questões moralmente problemáticas em jogo, valores relevantes para o indivíduo que serão considerados em sua decisão. Esses valores poderão estar na base das motivações de uma mulher para manter uma gravidez indesejada, uma gravidez relativamente à qual tem sentimentos e julgamentos ambíguos, uma gravidez que frustre o que entende como condições adequadas de vida para si ou para os indivíduos que lhe são próximos. Alguns exemplos são o valor moral da maternidade, valores relativos ao sexo e à sexualidade e, de maneira mais ampla e mais complexa, entendimentos específicos (e variáveis) sobre o que confere valor à vida.

Do fato de que as decisões dos indivíduos tenham uma dimensão moral não decorre que a questão do direito ao aborto seja de caráter moral. Em outras palavras, um indivíduo pode recorrer a valores e justificativas de caráter moral para tomar suas decisões e, caso deseje, para justificá-las para indivíduos que lhe sejam próximos ou publicamente. Mas o direito a decidir sobre manter ou não uma gravidez faz parte do direito a decidir sobre o próprio corpo, que por sua vez faz parte dos direitos individuais básicos. É possível argumentar, com base em noções de liberdade e de autonomia

Para uma introdução às teorias políticas feministas na qual esse argumento é trabalhado, cf. Miguel e Biroli (2014). 
individual fundamentais à tradição liberal, e, portanto, mesmo sem o tensionamento provocado pela incorporação das abordagens feministas, que o direito ao aborto é uma questão política e é incontornável para a democracia.

O direito ao aborto é de caráter político porque corresponde ao direito do indivíduo, no caso, das mulheres, para dispor de si e do seu corpo. A forma que assume, assim como sua recusa, tem impacto na definição dos direitos de cidadania, com a implicação adicional de que sua recusa impacta diferentemente mulheres e homens e, portanto, define clivagens nesses direitos. Se a decisão individual por realizar ou não um aborto pode ser vista como pessoal e moral, a afirmação ou recusa desse direito precisa ser politicamente definida e justificada.

Não pretendo, nem seria possível aqui, retomar de maneira sistemática posições e autores que constituem o que venho chamando de tradição liberal, e reconheço de antemão que não dou a atenção devida aos matizes internos a essa tradição. Parece-me, a despeito disso e de acordo com os objetivos deste artigo, que é possível e útil resgatar três entendimentos genéricos o suficiente para servirem de premissa para esta argumentação, sem que apresentem maiores problemas:

1. a democracia requer normas e instituições que validem e garantam direitos iguais de cidadania aos indivíduos, entre os quais se destaca a igual obrigação, e a igual liberdade, diante das leis;

2. a igualdade de direitos inclui, no caso dos adultos ${ }^{6}$, o direito a decidir autonomamente sobre o que se passa no e com seu corpo - em outras palavras, o direito a dispor autonomamente do seu corpo;

3. a democracia requer o Estado laico, sem o qual a igual liberdade de crença (e a liberdade para não crer), assim como a igual liberdade dos indivíduos para definir seu estilo de vida, é ameaçada.

Invertendo a sequência exposta, retomo primeiramente o que é apresentado no item 3, o entendimento de que a laicidade do Estado é um imperativo democrático (Miguel, 2012). A fundamentação de políticas e normas em dogmas religiosos fere a ideia de soberania popular sem a qual o ideal democrático cai por terra. Ela rompe com o horizonte normativo que define

\footnotetext{
6 Não considero que retirar as crianças de cena elimine as dimensões do problema que concernem a sua integridade física. Não se trata de suspender seu direito a dispor de seu corpo, mas de configurá-lo de acordo com as especificidades e formas de dependência que caracterizam a infância.
} 
como desejável a igual participação dos indivíduos na definição das normas que incidem sobre suas vidas, uma vez que as restrições nos direitos (e mesmo nos discursos e comportamentos) derivam de crenças que estariam acima da pluralidade dos valores e estilos de vida - numa das convergências que se definem entre o ideal democrático e os valores liberais no mundo moderno e contemporâneo. Acentuando esses valores, o respeito à pluralidade implica o respeito à independência individual, justificada não apenas pelo fato de que as pessoas são diferentes e podem eleger diferentes valores como prioritários na condução das suas vidas, mas também pelo entendimento de que indivíduos adultos têm maiores e melhores condições para avaliar o que é melhor para si e para "perseguir seu bem a seu próprio modo" (Mill, 2008 [1859], p. 15). As intervenções do Estado, das maiorias e de outros indivíduos são, assim, restritas com base na definição de que "sobre si mesmo, sobre seu próprio corpo e mente, o indivíduo é soberano" (Mill, 2008 [1859], p. 13). Em um registro distinto nessa mesma tradição, as restrições kantianas ao tratamento dos indivíduos como meios fornecem fundamentos para relacionar a integridade dos indivíduos, seu igual valor como seres humanos e seu controle sobre si. O direito à privacidade como uma das formas do direito a decidir sobre si está presente na legislação contemporânea sobre o aborto nos Estados Unidos. Nela, o direito ao aborto é codificado como direito à privacidade, fundamental portanto ao exercício da autonomia dos indivíduos ao garantir que as necessidades julgadas relevantes pelos próprios indivíduos, segundo os valores morais que lhes são caros, sejam protegidas das concepções majoritárias numa sociedade (Cohen, 1997) ${ }^{7}$.

Os argumentos religiosos mobilizados em oposição ao direito ao aborto, por sua vez, contradizem diretamente os entendimentos enunciados nos itens 1 e 2 . As restrições na autonomia das mulheres sobre sua capacidade reprodutiva e no direito a dispor do seu corpo rompem com a igual obrigação dos indivíduos às normas correntes, uma vez que incidem distintamente sobre

É importante distinguir claramente entre o direito à privacidade pessoal e o direito à privacidade de entidade (da família), que foi mobilizado, em diferentes contextos sociais e normativos, para justificar o controle sobre as mulheres. As garantias para a entidade familiar como sujeito (garantias de privacidade ou de decisão sobre a vida dos indivíduos que dela fazem parte) corresponderam historicamente ao isolamento da esfera familiar relativamente aos critérios de justiça. A criminalização da violência doméstica contra mulheres e crianças e do estupro no casamento só se tornou possível quando se rompeu com essa definição. Vale, assim, lembrar quais espectros nos rondam quando a valorização da família é proposta como base para leis e políticas. 
mulheres e homens, impondo às primeiras limitações e constrangimentos que não têm validade para os últimos. $\mathrm{O}$ direito a controlar o próprio corpo pode ser tomado como algo que está no cerne da individualização e do reconhecimento da capacidade de exercício da autonomia assim concebidas. A "propriedade de si", que podemos aqui definir para os propósitos desse texto como a autonomia dos indivíduos para dispor do próprio corpo, é uma das bases para o acesso à cidadania, e a criminalização do aborto gera uma assimetria, impondo às mulheres limitações no manejo do próprio corpo com as quais os homens não sofrem (Miguel, 2012). Sua recusa recoloca não apenas o problema das escolhas, ou das escolhas relativas à reprodução, mas todo o conjunto de direitos fundados na noção do indivíduo como agente moral autônomo.

Essa limitação nos direitos das mulheres contradiz, assim, os entendimentos contemporâneos de que a igual liberdade dos indivíduos depende do respeito a qualquer tipo de vida, desde que não seja imposta (Ronald Dworkin (2005 [2000], p. XVI), isto é, do respeito à capacidade moral dos indivíduos de fazer escolhas refletidas e responsabilizar-se por elas, fundamental na compreensão liberal da individualidade.

Os avanços históricos nas garantias aos direitos individuais tiveram como uma de suas linhas de força a vinculação entre tolerância e laicidade do Estado, em outras palavras, a separação entre religião e política. Sem ela, a ideia de que o respeito aos indivíduos inclui o respeito a seu julgamento sobre o que é importante para si perde força e sentido. Compreensões da maternidade, concepções determinadas da família, entendimentos sobre como se expressam a solidariedade e a bondade humanas, ou a ideia de que um embrião fecundado é a expressão da vontade de uma entidade supra-humana, têm peso e relevância variáveis na vida de diferentes indivíduos. Quando são mobilizadas para impor, aos indivíduos, uma forma de vida que não condiz com os valores que assumem como seus, há uma ruptura com a noção de individualidade que se constitui a partir desses marcos.

O direito a controlar o próprio corpo pode, ainda, ser definido a partir das seguintes premissas (aqui tomo por base, mas reelaboro, a discussão feita por Fischer, 2003):

(a) nenhum contato com o corpo do indivíduo pode existir sem seu consentimento (o que garante que exista uma noção clara de que qualquer contato não consentido equivale a uma violação); 
(b) o que ocorre ao e no corpo de um indivíduo deve ser uma decisão sua, consentida (o que inclui o direito a informações, fundamental quando se pensa nas formas do controle pelos profissionais da área de saúde e nas novas tecnologias reprodutivas);

(c) a decisão sobre manter uma gravidez, nutrir e sustentar biologicamente um outro indivíduo deve ser da mulher (o que garante que exista uma noção clara de que qualquer determinação heterônoma relativa a seu próprio corpo fere seu direito à autonomia);

(d) a, b e c devem ser não apenas garantidos no sentido negativo da liberdade que está aí envolvida - não criminalizados - mas também no sentido positivo, isto é, apoiados pelo Estado por meio de políticas públicas de combate à violência, de orientação para o respeito às decisões individuais, de fornecimento de recursos que tornam possível o controle dos indivíduos sobre sua capacidade reprodutiva independentemente da sua situação socioeconômica, de atendimento adequado na área de saúde. Se o direito a decidir sobre o próprio corpo existir em abstrato, mas não for garantida a sua efetividade, o direito dos indivíduos a autonomia continuará sendo ferido.

A passagem para $d$ implica deslocamentos em relação à concepção negativa da liberdade e a concepções restritas de autonomia individual, que avaliam sua existência e intensidade em escolhas pontuais e localizadas, tomando como referência a oposição entre escolhas voluntárias e coação (faço essa discussão em Biroli, 2013a e 2013b; ela também será retomada mais adiante neste artigo). Uma vez que essa visão restrita das escolhas individuais é ultrapassada, o problema da justiça ganha novos contornos. Ao mesmo tempo, a consideração da posição concreta das mulheres nas relações, em vez da manutenção de uma concepção abstrata do direito dos indivíduos a dispor de seu corpo, traz questões que não se fizeram presentes nesta seção.

\section{Aborto e autonomia nas teorias feministas: do indivíduo abstrato à posição social das mulheres}

A tradição liberal permite sustentar o direito ao aborto como direito à autodeterminação, com enfoque na soberania do indivíduo sobre seu próprio corpo. Entendo que esse passo é não apenas relevante neste debate, mas incontornável.

As abordagens feministas do aborto se definem em diálogo com as premissas baseadas nas noções liberais do direito dos indivíduos a dispor 
sobre seu corpo e são sem dúvida devedoras dos avanços que o liberalismo permitiu na construção de uma agenda - disputada e sem dúvida contraditória em muitos sentidos - para a garantia dos direitos individuais. Mas, ao problematizar o aborto a partir das experiências concretas e situadas das mulheres, essas abordagens tensionam os limites das noções liberais de indivíduo e de autonomia, iluminando dimensões da problemática do aborto que não são enfrentadas de maneira adequada e têm mesmo sua validade negada nos enquadramentos liberais ${ }^{8}$.

As posições contrárias ao direito ao aborto mobilizam valores familiares tradicionais, ou assim entendidos, e definem a opção pelo aborto como um desvio moral que seria característico da exacerbação do individualismo nas sociedades contemporâneas. Além da recusa à noção liberal do direito do indivíduo a dispor do seu corpo e a determinar seu estilo de vida de modo que seja condizente com valores morais que assume como seus, essas posições negam a validade das motivações das mulheres - e mesmo sua individualidade - no debate sobre o aborto. Os argumentos a seguir são representativos das posições às quais me refiro:

O critério básico de opção sobre a vida do filho é somente o interesse pessoal. Esse modo de opção caracteriza um individualismo radical. É como se o empresário dissesse: "a fábrica é minha e faço dela o que me aprouver"; o banqueiro afirmasse "o dinheiro é meu e o aplico onde quiser" ou o agricultor aclamasse "a terra é minha e nela faço o que bem entender". "O útero é meu e com o embrião faço o que quiser” significa a mais completa vitória do consumismo sobre o valor da vida. Nesse sentido a relação mãe-filho não é mais dimensionada em termos do amor entre seres humanos mas em função da propriedade privada, egoísta, hedonista e predatória. A mulher passa a ser possuidora de um filho-objeto, como possui um automóvel, um vestido, uma conta bancária. E o filho ou feto-objeto também passará a ser a premissa da criança-objeto que de acordo com o contexto político-social

Embora seu foco seja prioritariamente no estupro e na barriga de aluguel, Anne Phillips (2013) apresenta preocupações semelhantes às que me motivam nesta discussão quando opta por uma noção de integridade individual informada pelas problematizações feministas da experiência vivida corporificada (lived bodily experience) das mulheres. Essa posição não abandona as concepções liberais de indivíduo, mas questiona as premissas que definem a autonomia como isolamento e o corpo como propriedade de si e como território demarcador da individualidade. Para uma análise que discute a relação entre autonomia e experiência vivida no feminismo a partir das obras de Simone de Beauvoir, Iris Young e Catharine MacKinnon, cf. Biroli (2013a, cap. 2). 
e pessoal poderá, como um objeto qualquer, vir a ser eliminado (Cunha, 2007, grifos retirados).

$\mathrm{Na}$ contramão dessa recusa aos direitos individuais das mulheres, as abordagens feministas do aborto se situam, ao mesmo tempo, no registro liberal desses direitos e no de críticas que tensionam a tradição liberal ao tomar como ponto de partida a posição social concreta das mulheres. A afirmação do direito de escolha, conjugada à do direito ao corpo, é pensada, assim, a partir de premissas características dos enfrentamentos e problematizações na teoria feminista: a noção liberal de indivíduo, que é fundamental em muitos sentidos para garantir direitos básicos de cidadania às mulheres, apresenta limites quando é tomada em termos abstratos. Se, por um lado, pode ser estratégica para superar diferenças entre mulheres e homens (e entre as mulheres) - superando as implicações da atribuição de sentidos distintos ao corpo das mulheres e ao dos homens e os obstáculos à participação das primeiras na vida pública por serem mulheres -, a concepção abstrata dos indivíduos pode servir para justificar desigualdades na medida em que não enfrenta as diferenças nas vivências de umas e de outros em sociedades nas quais o gênero é uma variável central na definição da posição relativa dos indivíduos. Em outras palavras, o problema se coloca porque a universalização dos direitos, que está sem dúvida além das normas atuais relativas ao aborto no Brasil hoje, não permite confrontar obstáculos à construção da igualdade de gênero que permanecem a despeito dela.

Quando a universalidade é definida como suspensão das particularidades, são suspensos aspectos relevantes das diferenças atuais entre mulheres e homens, diluindo assim problemas que incidem sobre as mulheres por serem mulheres, em sociedades nas quais o gênero é uma dimensão importante das posições e das vantagens dos indivíduos. É o que ocorre na obra de um dos autores de maior expressão no pensamento liberal contemporâneo, John Rawls (1971), quando procura avançar na crítica às desigualdades como obstáculos à garantia das liberdades individuais por meio de uma adesão estrita ao paradigma da justiça como imparcialidade. A posição singular das mulheres não é validada como relevante na construção do problema das desigualdades. Com isso, o problema político dos constrangimentos que ampliam as dificuldades das mulheres, relativamente aos homens, para vocalizar suas experiências e interesses na esfera pública também perde va- 
lidade. As mulheres são, assim, colocadas diante da opção de tomar parte da esfera pública como se fossem homens ou ver recusadas suas vivências, visões e interesses como externos à dimensão da justiça e aos limites da política. Mesmo as abordagens feministas que mantêm em algum grau a adesão ao ideal da justiça como imparcialidade o assumem considerando a tensão que existe entre a adoção do indivíduo abstrato como referência e a possibilidade de individualização das mulheres, isto é, de que as mulheres sejam sujeitos de direito sem o apagamento da sua posição e das suas experiências (penso na abordagem de Susan Okin, 1989a, 1989b e 1999).

$\mathrm{Na}$ confrontação com as noções abstratas do indivíduo, tem um papel central a crítica à dualidade entre as esferas pública e privada, com a politização do que ocorre na primeira e o entendimento de que o modo de organização de uma delas está vinculado, permanentemente, ao modo de organização da outra. As hierarquias e o grau de liberdade dos indivíduos na esfera privada têm impacto direto sobre sua vida na esfera pública e no processo de construção de suas identidades. O direito ao aborto pode ser, assim, situado em um domínio da vida e das escolhas individuais que é profundamente pessoal, ao mesmo tempo em que é político. Uma das críticas ao enquadramento liberal do direito ao aborto, sobretudo na forma do direito à privacidade, é que a dualidade entre a esfera pública e a privada pode ser mantida intacta, pouco fazendo para tornar efetivo o acesso a esse direito e para romper com as injustiças que organizam os limites à autonomia das mulheres na sexualidade e na reprodução ${ }^{9}$.

As teorias feministas também impactam o debate a partir da crítica à noção de escolha voluntária tomada como critério para a avaliação do grau de liberdade garantido aos indivíduos. Essa crítica desloca o foco do momento em que a escolha se dá para o contexto em que as preferências são produzidas. Ganham peso, nesse caso, os constrangimentos - que não coincidem necessariamente com coerção - que restringem as alternativas e dão forma ao horizonte de possibilidades considerado pelas mulheres. Ainda nesse ponto, uma outra questão se coloca, a das consequências das escolhas realizadas. As

Esses argumentos são mobilizados nas críticas à decisão da Suprema Corte que legalizou o aborto nos Estados Unidos no famoso caso Roev. Wade, de 1973, mas sobretudo em Harris v. McRae, de 1981, que adicionou à primeira decisão o entendimento de que o Estado não tem de prover os recursos para o aborto. Assim concebida, a legislação preservaria intacta a oposição entre público e privado e as formas de opressão a que corresponde, além de não avançar na garantia efetiva desse direito. Para um inventário posicionado dessas críticas, conferir Cohen, 1997, e Cornell, 1998). 
mulheres ganham centralidade nessas abordagens como indivíduos, como a posição legítima a partir da qual interesses e implicações do contexto de produção das preferências e realização das escolhas são considerados (discuto esse deslocamento, de diferentes perspectivas, em Biroli, 2013a e 2013b, numa posição que dialoga especialmente com as contribuições de Pateman, 1985 [1979], 1989 e 2009 [2002], Nussbaum, 1999, e Friedman, 2003).

A tematização do direito ao corpo, em termos abstratos, pode dizer pouco sobre a posição das mulheres, suas motivações e o contexto das suas decisões. Um problema que pode ser colocado, nesse ponto, é o da definição dos critérios a partir dos quais os dilemas morais e os problemas políticos são construídos. É relevante, para a crítica aos limites da democracia, que se discuta se as motivações dos indivíduos são consideradas no debate público e na construção das normas que os afetam. No caso do aborto, em que o modo de construção do problema e as convenções e normas incidem diretamente sobre as mulheres, sobre seu corpo, sua integridade física e psíquica e sobre sua trajetória, a relevância da inclusão das motivações ou, se quisermos, da presença ou não da posição específica e concreta dos indivíduos como ponto de partida é patente. A manutenção ou interrupção de uma gravidez tem um impacto distinto, para as mulheres, daquele que tem para os homens porque afeta diferentemente sua integridade física (Thomson, 1971) e as restrições no direito ao aborto incidem, portanto, de maneiras distintas para mulheres e homens. O ponto de partida, nesse caso, não é o indivíduo em abstrato e descolado das relações, mas também não é o feto ou uma relação idealizada entre a "mulher-como-mãe" (um papel social) e o feto.

A linguagem da escolha individual é vista como insatisfatória tanto nas abordagens com foco nas formas estruturais e cotidianas da dominação masculina (como as de Catharine MacKinnon e Carole Pateman), quanto naquelas que destacam o fato de que essa dominação recai distintamente, e é vivida e significada de maneiras muito distintas, pelas mulheres segundo sua raça e classe social (remeto aqui a Bel Hooks e Angela Davis). Sobretudo quando o aborto é criminalizado, mas mesmo quando deixa de ser crime sem que se defina uma política de igualdade no acesso aos serviços médicos e hospitalares, ele se define como alternativa em condições bastante distintas se as mulheres são brancas ou negras, se estão entre os grupos mais ricos ou mais pobres na sociedade. Para as que estão em posição desvantajosa inclusive relativamente a outras mulheres, "o aborto pode ser mais um in- 
dicativo de desigualdade social, limitações sociais e injustiça reprodutiva" (Higgins, 2006, p. 39).

A consideração da relação entre aborto e injustiças está, inclusive, na base de uma posição feminista reticente ao direito ao aborto, como a de Catharine MacKinnon (1987). Nesse caso, o problema antes indicado do contexto em que as escolhas se fazem, assim como o das consequências dessas escolhas, é trazido para a linha de frente de uma abordagem que entende que a liberdade das mulheres é restrita quando as desigualdades de gênero, e a dominação masculina, organizam suas possibilidades e definem quais serão os custos das suas decisões. Se na ampla maioria das abordagens feministas sobre o aborto, autonomia reprodutiva e liberdade sexual caminham juntas na demanda de maior controle das mulheres sobre seu corpo, nesse caso a liberdade sexual não é tomada como algo intrinsecamente positivo porque pode estar subordinada a uma gramática masculina da sexualidade. Em outras palavras, o domínio pelo sexo e a objetificação das mulheres poderiam ser facilitados pelo aborto - que seria mais um desdobramento dessas relações de poder do que de escolhas autônomas das mulheres.

Como as consequências das relações sexuais são distintas para mulheres e homens, tanto fisicamente quanto nos seus projetos de vida, o peso da decisão de abortar ou a responsabilidade pela criação de um filho em condições muitas vezes indesejáveis recairiam sobre as mulheres. Nesse entendimento, o domínio no âmbito da sexualidade se torna a questão central para uma justiça que toma as vivências das mulheres como pontos de partida: "enquanto as mulheres não controlam o acesso a sua sexualidade, o aborto facilita a disponibilidade sexual das mulheres" (MacKinnon, 1987, p. 99). O sentido da liberação sexual em contextos nos quais há desigualdade de gênero seria, portanto, o de uma liberação ainda maior para a agressividade masculina (MacKinnon, 1987, p. 99).

Discordo dessa aproximação da questão do aborto, mas entendo que ela colabora para trazer à tona uma questão relevante: as escolhas não se dão de maneira isolada das relações de poder. O contexto em que as escolhas se definem, assim como suas consequências, são incontornáveis quando se toma a posição das mulheres como válida na construção do problema do aborto e, em especial, quando se define a dominação masculina como um problema para a democracia, em vez de suspendê-la como questão. Além disso, essa perspectiva pode ser importante para se lidar com o fato de que há obstáculos diferenciados para o exercício da autonomia por mulheres e 
homens, assim como são também distintos os desafios para a legitimação das experiências e perspectivas de mulheres e de homens no debate público e na construção da agenda política. Um dos problemas na análise de MacKinnon é que ela considera a posição das mulheres como dominadas, mas restringe o caminho para a incorporação das suas motivações - no caso, na realização de um aborto - uma vez que vê suas ações como desdobramentos das relações de dominação às quais estão submetidas.

Uma alternativa distinta, e que entendo que tem maior potencial na problematização da relação entre aborto, autonomia e democracia, é reconhecer a centralidade das motivações e justificativas expressas pelas mulheres, tomando-as como ponto de partida para discutir a dimensão moral e ética do aborto. O potencial da crítica poderia ser, assim, mantido, mas se evitaria a tentação de definir razões heteronomamente. A crítica da dominação se faria, assim, em ruptura com a noção de razão abstrata como a base para a justiça, em uma visão da democracia que requer a consideração das experiências e perspectivas plurais dos indivíduos e valoriza sua vocalização pelos próprios indivíduos. É uma posição que me parece bem representada pelo entendimento de que os indivíduos não "raciocinam a partir de pressupostos idênticos" (Young, 1990, p. 101) e não são atingidos de modo homogêneo pelos entraves à construção autônoma das suas vidas. A agência existe, assim, em condições variáveis, o que procurei expressar com a noção de "agência diferenciadamente imperfeita" (Biroli, 2013a, cap. 1) e que é exposto na afirmação de Phillips (2013, p. 8-9) de que "todos têm agência, e que se as pessoas são menos ou mais bem informadas, menos ou mais constrangidas pelas circunstâncias, se defrontam com um conjunto menor ou maior de alternativas, a ampla maioria de nós é de agentes pensantes que fazem uma escolha”, e isso não significa em qualquer medida que a crítica às restrições diferenciadas a essas escolhas não deva ser feita.

O ponto para esta discussão é que o contexto concreto em que as escolhas, e as motivações, se definem passa a ser incontornável. Por um lado, isso e necessário para situar as escolhas no âmbito da justiça, discutindo as condições em que se efetivam e suas consequências. Por outro, desloca o problema do registro da variedade das concepções individuais de bem para o da construção de uma ética fundada nas experiências diferenciadas, nesse caso nas experiências diferenciadas das mulheres na sociedade.

É para esse segundo deslocamento que me volto agora, analisando as formas que assume nas abordagens da chamada "ética do cuidado". Sob essa 
rubrica, são reunidas abordagens distintas entre si, sobretudo no modo (e no quanto) mobilizam as convenções de gênero associadas à maternidade. Em algumas delas, a distinção entre uma ética centrada no cuidado e uma ética da justiça ou dos direitos corresponde a um afastamento da ideia de autonomia individual. A noção de autonomia que toma forma no pensamento liberal seria contrastante com a posição social efetiva das mulheres: isso se daria não apenas porque os obstáculos ao exercício da autonomia seriam distintos para elas, mas também pelo horizonte ético que se definiria quando são ouvidas e quando suas experiências são levadas em conta na afirmação dos valores socialmente relevantes. A partir da singularidade das suas experiências, as mulheres mobilizariam valores que colocam em xeque a autonomia individual como referência normativa. Responsabilidade, zelo e cuidado com as outras pessoas, sobretudo com as mais vulneráveis, estariam no centro desse horizonte ético. Em algumas dessas abordagens, a maternidade é elevada à posição de experiência que singulariza as mulheres - daí a noção de maternalismo ou pensamento maternal ${ }^{10}$. Ainda que essa não seja uma orientação geral dessas discussões, ela abre caminho para enquadramentos que têm implicações negativas da perspectiva das garantias aos direitos das mulheres, em que o aborto é pensado a partir do valor da vida do feto (Elshtain, 1981, p. 312 e 313) e tradições comunitárias e concepções idealizadas da família são valorizadas.

Numa linha distinta, são particularmente interessantes os estudos de Carol Gilligan, que estiveram na base do debate sobre "ética do cuidado" no feminismo, mas não podem ser identificados com o maternalismo. Com base em entrevistas com mulheres que consideravam a alternativa de abortar, em um estudo focado na "relação entre julgamento e ação" (Gilligan, 1982, p. 72), a autora vê nos dilemas relativos ao aborto, tais como definidos pelas próprias mulheres, a expressão de uma "linguagem moral distinta"11.

O ponto de partida de Gilligan para essa discussão é a teoria dos estágios morais do filósofo e psicólogo estadunidense Lawrence Kohlberg (1981), que define a passagem do estágio pré-convencional para os estágios convencional e pós-convencional da moralidade como uma dinâmica que refletiria a expansão

${ }^{10}$ Cf. especialmente Elshtain (1981) e Ruddick (1989), mas também as discussões reunidas em Held (1995) e apresentadas por Clement (1996).

11 O estudo é baseado em entrevistas com 29 mulheres, feitas durante o primeiro trimestre de gravidez, quando definiam sua posição sobre a manutenção da gravidez ou realização de um aborto, e no final do ano seguinte (Gilligan, 1982, p. 72). 
da capacidade de raciocínio moral do indivíduo para a sociedade e, finalmente, para um ponto de vista universal (Gilligan, 1982, p. 73). A partir dessas entrevistas e de trabalhos realizados conjuntamente com Kohlberg, Gilligan assumiria que essa teoria expressa um tipo de desenvolvimento moral, o da justiça e dos direitos, fundado no raciocínio moral dos homens e não em padrões universais do desenvolvimento. Rompe, assim, com a visão de que o raciocínio das mulheres expressaria uma falha ou desvio. Há, de fato, diferenças, e elas expressam problemas, mas não na forma de raciocinar das mulheres: trata-se de limitações nas teorias. Por outro lado, as mulheres teriam de fato maior dificuldade para "falar publicamente em sua própria voz", não por uma falha, mas devido a "constrangimentos a elas impostos pela sua falta de poder e pela política das relações entre os sexos" (Gilligan, 1982, p. 70). O fato de serem pouco ouvidas e de serem raramente a fonte das motivações e justificações consideradas publicamente para a análise de dilemas morais e questões políticas acentua essa condição.

Ouvir as mulheres se torna, portanto, um requisito para ultrapassar a falsa universalidade dos critérios que se definem a partir das experiências dos homens. A voz das mulheres não levaria a uma essência ou autenticidade feminina, mas permitiria acesso ao que singulariza sua posição como indivíduo. Abordagens posteriores estabeleceriam uma relação entre essa singularidade e sua posição como parte do grupo "mulheres"12. Em Gilligan, o problema se coloca na tensão entre o reconhecimento de formas de pensar singulares às mulheres - por serem mulheres e estarem, portanto, posicionadas de modo distinto dos homens nas relações sociais - e os limites e potenciais de individualização das mulheres, considerando as relações de gênero mas também os critérios correntes para sua análise.

A decisão relativa ao aborto é vista como um caso privilegiado para a observação de como as mulheres pensam em uma situação que, além de moralmente complexa, é marcada pela expectativa de que a decisão tomada seja de fato sua. Esse contexto, que é o do acesso a métodos anticonceptivos e ao aborto legal nos Estados Unidos na passagem dos anos 1970 para os anos 1980, colaboraria para individualizar a mulher em um processo de escolha que a coloca no centro da decisão a ser tomada, como protagonista da sua

12 Remeto à compreensão de Iris Young: "dizer que uma pessoa é uma mulher pode antecipar algo sobre os constrangimentos e expectativas em geral com os quais ele precisa lidar. Mas não antecipa qualquer coisa em particular sobre quem ela é, o que ela faz, como ela vivencia sua posição social" (Young, 1997, p. 32). Em outras palavras, as marcas de gênero não podem ser evitadas, mas o modo como o gênero marca uma vida individual é específico e variável (Young, 1997, p. 33). 
vida reprodutiva. Por outro lado, as convenções que associam o feminino a virtudes que estariam relacionadas à capacidade de autossacrifício - vale lembrar, diretamente relacionadas ao ideal moderno da maternidade impõem às mulheres conflitos singulares na forma de uma oposição entre interesses próprios e interesses das outras pessoas, entre autonomia e compaixão (Gilligan, 1982, p. 70-1). O ponto, para Gilligan, é que a afirmação do direito de escolher, assim como a afirmação pública de que a assertividade no julgamento e nas ações são características da vida adulta, está em conflito com as formas convencionais da feminilidade, que estariam presentes de maneira acentuada na socialização das mulheres.

Colocadas diante da alternativa de interromper ou não uma gravidez, as mulheres entrevistadas por Gilligan codificam o problema com que se defrontam pelos registros da obrigação moral de "exercitar o cuidado" e de, ao mesmo tempo, evitar danos às pessoas (Gilligan, 1982, p. 73). A autora identifica uma sequência que inclui um primeiro momento, no qual o foco é na autopreservação ou sobrevivência, um segundo momento no qual um conceito de responsabilidade é elaborado, porém fundido com uma moralidade maternal convencional - na qual a preocupação consigo é vista como egoísmo -, e um terceiro momento no qual as relações são reconsideradas (e não abandonadas, é importante dizer), passando a incluir as mulheres como sujeitos das escolhas que são feitas. Em sua formulação do que se dá, "o cuidado se torna o princípio de julgamento autoescolhido que permanece psicológico na sua preocupação com as relações e na sua reação, mas se torna universal na sua condenação da exploração e dos danos causados" (Gilligan, 1982, p. 74). Não haveria, nessa configuração do problema, uma exclusão da ética fundada nos direitos, mas uma integração de direitos e responsabilidades em formas de raciocinar que dão centralidade às relações.

Nesse processo, o que está em questão é a legitimidade da autoexpressão, não como uma forma de expressão autêntica, mas como possibilidade de singularização. Trata-se da possibilidade de expressão de preferências assumidas pelos indivíduos como suas, caso em que as escolhas realizadas a partir dessas preferências seriam também codificadas como escolhas que atendem aos seus próprios interesses. Ao ultrapassarem a oposição entre autossacrifício e individualização, entre uma forma de entendimento do sentido moral das escolhas (pela recusa dos próprios interesses) e a legitimidade da autoexpressão, as mulheres se afirmariam como "pessoas mais singulares" 
(do depoimento de Sarah em Gilligan, 1982, p. 93). A responsabilidade para com os outros é equacionada juntamente com a responsabilidade para consigo mesmas, permitindo "fazer o que você quer porque você sente que suas aspirações e necessidades são importantes" (Gilligan, 1982, p. 94).

Não estamos no terreno da recusa aos direitos individuais das mulheres - codificados no pensamento conservador como uma forma de egoísmo -, mas são claras as diferenças em relação aos argumentos fundados na noção de propriedade de $\mathrm{si}^{13}$, nos quais as relações e as responsabilidades para com outras pessoas não têm lugar ou, ao menos, não ganham centralidade a não ser negativamente - em que os outros são aqueles a quem não nego a possibilidade de que exerçam sua liberdade ao exercer a minha.

As entrevistas feitas por Gilligan mostram que, quando se desloca o problema do aborto da díade "mulher-como-mãe"-"feto-como-filho", não apenas a mulher é individualizada de outra forma, como ganham importância vários indivíduos a ela relacionados. É importante, no entanto, observar que essas relações não são apenas de afeto e preocupação recíproca. Entre as mulheres entrevistadas, são comuns as preocupações com as consequências da manutenção da gravidez para si e para seu companheiro e filhos, numa perspectiva que leva em conta o sustento material, sua possibilidade de atenção e cuidado com esses outros, assim como o equilíbrio entre a atenção a esses familiares e a manutenção de suas atividades profissionais. Mas há uma série de entrevistas nas quais aparecem outras facetas dessas relações: a pressão de amantes para que as mulheres realizem um aborto e a pressão dos pais, no caso das mulheres jovens e adolescentes, para que abortem por não terem uma situação afetiva estável e não terem engravidado numa relação conjugal "legítima" e socialmente aceitável, são exemplos frequentes. Nesses casos, há uma tensão entre a escolha autônoma das mulheres e o peso de motivações que remetem à dupla moral sexual e às convenções de gênero a ela relacionadas.

Parece importante, aqui, como em discussões apresentadas na primeira seção, ressaltar que, quando se enquadra o problema do aborto pela perspectiva da autonomia das mulheres, tanto a recusa desse direito quanto as pressões para que se realize são problemáticas. As entrevistas permitem considerar que a via do "autossacrifício" pode estar presente tanto na decisão por não abortar quanto na decisão por realizar um aborto. A "voz femini-

${ }_{13}$ Para outras perspectivas críticas feministas da noção de propriedade de si, cf. Pateman (2009 [2002]) e Phillips, 2013. 
na" que emerge em muitos depoimentos corresponde a uma equação entre a preocupação com os outros e formas convencionais da "reputação" (do depoimento de Anne em Gilligan, 1982, p. 79) e da respeitabilidade, que se apoiam na recusa à individualização das mulheres como sujeitos autônomos. O ideal da maternidade e o custo social da recusa a aderir a esse ideal incidem nos sentidos atribuídos ao aborto ${ }^{14}$. O controle social sobre seu corpo, mobilizado de diferentes formas pelo Estado, mas também por aqueles que lhes são próximos - pais, maridos, namorados, amantes - está na base de reivindicações morais que se impõem às mulheres, constrangendo-as, mas podem também compor o modo como raciocinam sobre o aborto.

O foco não está, portanto, apenas no aborto como alternativa socialmente disponível, mas no aborto como alternativa que se viabiliza em condições e contextos nos quais pode ser considerado pelas mulheres autonomamente e disponibilizado sem constrangimentos e com segurança. Essa discussão amplia e complexifica a problemática da escolha voluntária, no sentido que venho discutindo aqui e em outros textos (Biroli, 2013a e 2013b). Quando as alternativas entre acesso e proibição, entre escolha voluntária e coerção, são deslocadas para a análise dessas escolhas, ganham destaque o contexto no qual as preferências são produzidas, o horizonte de possibilidades e a economia material das escolhas. Além do que constrange e dá forma às escolhas, entra em cena também o problema das implicações das escolhas realizadas, como dito anteriormente. O sexismo, as desigualdades e as formas de construção do feminino a partir do olhar dos homens em contextos nos quais a dominação masculina tem impacto na construção simbólica e material do gênero fazem parte também das políticas do aborto. Não são suspensos nas situações concretas nas quais as decisões são tomadas e nas relações que permeiam essas decisões e a realização (ou não) de um aborto. Esse contexto situa as relações, não apenas com familiares e amantes - que são certamente multifacetadas e não se restringem a um ideal afetivo, em que amor e reciprocidade organizam as considerações de uns pelos outros -, mas também com agentes públicos da área de saúde.

$\mathrm{Na}$ "ética do cuidado" assim definida, as relações e a intersubjetividade precedem a individualidade, mas o foco nas experiências das mulheres faz

14 "Eu não estava fazendo isso tanto por mim mesma, eu estava fazendo pelos meus pais. Eu estava fazendo porque o médico me disse para fazer, mas eu nunca tinha, na minha cabeça, tomado a decisão de que eu estava fazendo isso por mim. Na verdade, eu tinha que me sentar e admitir, 'Não, eu realmente não quero adentrar a seara da maternidade agora. Eu honestamente não sinto que eu quero ser mãe"' (depoimento de Sandra em Gilligan, 1982, p. 86). 
com que o peso das relações não dilua a singularidade da posição das mulheres nessas relações ou invisibilize as relações de poder. A análise de Gilligan, a seu modo e com seus limites, incorpora a relação entre as decisões das mulheres, os sentidos assumidos pelos papéis de gênero e os constrangimentos e obstáculos ao exercício autônomo das escolhas em contextos concretos.

É um caminho bastante distinto daquele assumido pelo comunitarismo em sua ênfase na intersubjetividade, em que o peso dos sentidos que se pressupõe que sejam compartilhados pela comunidade faz suspender a singularidade das experiências das mulheres. O problema político que venho apresentando a partir das abordagens feministas, em que as experiências e motivações das mulheres estão em conexão com o problema da autonomia, desaparece nesse caso. Essa distinção é importante para os argumentos aqui trabalhados. Para autores como Michel Sandel e Charles Taylor, a escolha tem como pano de fundo problemas cuja significação eu não determino individualmente. Não é, por enquanto, algo que não pudesse ser assumido por abordagens feministas aqui apresentadas, e não me refiro apenas a Gilligan. O caráter social dos sentidos, no entanto, se define numa espécie de tensão entre valores e demandas "coletivas", situadas em comunidades específicas, e a forma como o self os mobiliza, vendo-os como algo que faz sentido para si (Taylor, 1991, cap. 4). O fato de que o "coletivo" não é homogêneo, nem mesmo numa comunidade reduzida, e o de que as implicações dos sentidos que assim se definem podem ser bastante distintas para mulheres e homens, não são discutidos.

A crítica à razão instrumental e à valorização do "modelo desengajado do sujeito humano" (Taylor, 1991, p. 101) corresponde nesse caso a uma crítica ao valor da autonomia individual de tipo diferente da que discuti antes. Em Gilligan (1982), a crítica à justiça fundada em um suposto raciocínio moral "universal" requer o reconhecimento de outras formas desse raciocínio, fundadas nas experiências e motivações das mulheres. Produz-se, assim, uma singularização que pode ser tomada como a base para a construção da justiça e da democracia. No comunitarismo, ao contrário, o resultado é o apagamento da posição e dos interesses das mulheres em uma forma de conceber o "coletivo" que é ancorada em valores tradicionais.

O aborto surge como exemplo, na discussão de Taylor, como controvérsia especial por expor com clareza "a natureza teísta ou secular dos fundamentos de uma pessoa" (Taylor, 2005 [1994]), o que não seria comum em outras circunstâncias e embates. Posteriormente, seria um exemplo 
das contradições presentes no "individualismo da autorrealização"15, que atravessariam diferentes formas - e "alinhamentos cruzados" - da crítica à razão instrumental e ao desencantamento do mundo na sociedade estadunidense contemporânea. Isso se expressaria na defesa, pela direita, de comunidades tradicionais "enquanto ataca o aborto voluntário e a pornografia”, defendendo também formas agressivas do capitalismo que contribuiriam justamente para dissolver as tradições que valoriza (Taylor, 1991, p. 95) ${ }^{16}$. Ao mesmo tempo, "do outro lado, encontramos apoiadores de uma posição atenta e mesmo reverencial à natureza, que iriam às últimas consequências para defender o habitat da floresta, manifestando-se a favor do aborto voluntário, com base no entendimento de que o corpo da mulher pertence exclusivamente a ela", o que seria resumido como uma posição que se opõe ao capitalismo selvagem mas adere ao individualismo possessivo de maneira mais radical que os maiores defensores do capitalismo (Taylor, 1991, p. 95).

A construção do problema do aborto a partir do debate feminista apresenta deslocamentos, e uma complexidade adicional, ao entendimento do que está em questão quando se discute o direito de uma mulher ao interromper uma gravidez. Esses deslocamentos se devem, sobretudo, ao fato de que seu ponto de partida é a experiência das mulheres, com sua posição específica nas relações de poder em sociedades nas quais o gênero incide sobre a trajetória e as alternativas disponíveis para os indivíduos. Não se trata, assim, de uma posição antagônica aos direitos individuais e à afirmação do valor da individualidade, mas de uma construção alternativa dos seus sentidos a partir das experiências concretas das mulheres.

\section{Conclusão}

Nesta discussão, assumo uma posição clara a favor do direito ao aborto

\footnotetext{
${ }^{15}$ Em inglês, self-fulfilment.

${ }^{16}$ Algo semelhante ocorre nas clivagens atuais da política do aborto no Brasil. O candidato à Presidência pelo Partido Social Cristão (PSC) nas eleições presidenciais de 2014, pastor da Igreja Universal do Reino de Deus, tem uma plataforma na qual o "direito à vida", item prioritário na construção da sua candidatura, e a defesa do capitalismo e do Estado mínimo convivem harmonicamente. As posições favoráveis ao direito ao aborto perderam, progressivamente, espaço e prioridade nas agendas de candidatos e partidos políticos no Brasil, retirando a singularidade à posição do candidato do PSC, uma vez que a convivência entre posições contrárias ao aborto e a defesa de um Estado bastante reduzido, em que prevalecem as soluções e mercado, poderiam ser atribuídas também a candidaturas mais identificadas com visões liberais do Estado e dos direitos individuais.
} 
como um direito de cidadania. Sem ele, fica comprometido o igual exercício da autonomia pelos indivíduos porque são definidas limitações, seletivas e segundo o seu sexo, no direito básico a disporem de seu próprio corpo.

Assumindo que o tema do aborto é moralmente controverso, mas incontornável para a democracia, discuti diferentes abordagens da relação entre aborto e autonomia. Meu objetivo não foi apresentar um mapa amplo dessas posições, mas mostrar as principais linhas de força que fundamentam o direito ao aborto na tradição liberal e, em especial, quais são os deslocamentos que se apresentam quando as teorias feministas elaboram a problemática do aborto tomando como ponto de partida as experiências e motivações das mulheres. O debate sobre aborto é modificado e alargado quando se considera, ao mesmo tempo, o direito das mulheres como indivíduos e o fato de que a incorporação de sua posição social tensiona a noção abstrata de indivíduo. Do mesmo modo, a relação entre o universal e o singular é tensionada, o que no debate sobre aborto implica repensar a noção de autonomia, mas sobretudo o que é necessário ao seu exercício.

Quais experiências ganham validade quando se discutem os direitos das mulheres? Quais motivações são consideradas legítimas, e quem as vocaliza? Por que a noção de individualismo como egoísmo é mobilizada pelos atores religiosos para discutir as decisões das mulheres, mas não para discutir as decisões tomadas pelos homens e sua escala de prioridades? Os julgamentos e expectativas na individualização das mulheres e dos homens parecem ser bastante distintos e certamente o são quando reprodução e aborto estão em questão.

É o que procurei mostrar a partir das análises sobre a justiça no acesso ao aborto e sobre o grau diferenciado de autonomia das mulheres diante das formas de controle existentes. Além desse caminho, que tematiza o contexto em que as escolhas se efetivam e suas implicações, deslocando as concepções de justiça ao confrontar a dualidade entre escolha voluntária e coerção, apresentei também os argumentos da "ética do cuidado" no sentido definido por Carol Gilligan. Nesse caso, a incorporação da posição social concreta das mulheres torna visíveis relações que não são consideradas quando o foco é no indivíduo isolado ou na relação entre "mulher-como-mãe" e feto. Outras pessoas, e outros sentidos das relações e do valor da individualidade, emergem nesses estudos.

Parece-me que também o valor da vida ganha sentidos distintos conforme se considere ou não a posição das mulheres e suas motivações, e é com breves 
considerações sobre esse ponto que termino este artigo. O valor da vida é mobilizado sobretudo pelos grupos religiosos em sua oposição ao aborto. O direito das mulheres de definir o que se passa com seu corpo e qual será sua trajetória é construído como oposto à preservação da vida (do feto) e, nesse sentido, como uma espécie de direito de morte. É possível considerar, no entanto, que o valor da vida atravessa diferentes elaborações e posições no debate sobre aborto, estando presente tanto entre aqueles que se apoiam em fundamentos religiosos quanto entre aqueles que se apoiam em fundamentos seculares (Dworkin, 2009 [2003], Taylor, (2005 [1994]). De um lado, esse reconhecimento pode ser importante para expor as estratégias dos grupos religiosos, que restringem o sentido da vida, procurando construir negativamente as posições favoráveis ao direito ao aborto. De outro, parece importante deixar claro que a história das garantias políticas seculares aos indivíduos está baseada fundamentalmente em uma valorização ímpar da vida de cada indivíduo. Não pretendo diluir as diferenças entre as posições, mas expor os limites dos argumentos religiosos que mobilizam noções restritas da vida.

O direito ao aborto é necessário para a valorização da vida - dos indivíduos, como cidadãos aos quais são garantidos direitos iguais e igual respeito a sua integridade física e psíquica. Faz toda diferença, para este debate, se a vida é concebida como algo sagrado e que está fora do arbítrio humano porque toda a vida é criação divina, se é uma abstração que engloba toda e qualquer vida humana independentemente da consciência e da vontade posição que tem sido mobilizada em conjunto com a primeira -, ou se o valor da vida se define no respeito aos seres humanos como indivíduos concretos, como sujeitos corporificados de projetos e interesses, como sujeitos que têm relações afetivas e são capazes de refletir sobre elas e sobre sua posição (e as consequências das suas ações) em relação às outras pessoas. Se este último entendimento não é um ponto de chegada, ele é sem dúvida o único ponto de partida possível para a consideração do problema do aborto quando autonomia individual e democracia são valores de referência.

Esse sentido da vida não restringe a discussão a indivíduos isolados e fundamentalmente desinteressados e descuidados uns com os outros. Mas, é preciso deixar claro, a consideração das relações como parte dos dilemas morais do aborto não implica a exclusão da singularidade e do direito ao exercício da autonomia, como procurei mostrar. O valor da vida, como emerge 
aqui, não depende da noção abstrata do indivíduo, e menos ainda da pressuposição do seu isolamento. Ao contrário, é "a disposição cega para sacrificar as pessoas em nome da verdade” que impõe riscos (Gilligan, 1982, p. 104).

As posições contrárias ao direito ao aborto promovem uma visão pouco refletida sobre o valor da vida, que não permite avançar na consideração sobre as vidas já presentes e existentes, sobre a inviolabilidade da vida como investimento humano e criativo (Dworkin, 2009 [1993]). A integridade dos indivíduos depende do respeito a sua integridade física e psíquica, à sua vida biológica e criativa, com os componentes psicológicos, afetivos e solidários que constituem a individualidade. $\mathrm{O}$ respeito à vida assim concebida depende, portanto, da redução dos obstáculos materiais e simbólicos a uma integridade que tem formas bastante concretas e terrenas.

Intrinsecamente relacionada à recusa à integridade e cidadania das mulheres, a concepção de vida mobilizada em oposição ao direito ao aborto respalda o sexismo. Em vez do direito das mulheres a decidir sobre si e sobre o que se passa em e com seu corpo, ganha centralidade a afirmação de que esse corpo tem significados que o tornam alheio à própria mulher - a santificação da maternidade e a objetificação da mulher pela perspectiva masculina fazem parte de uma mesma gramática que nega às mulheres o direito a autonomia. $\mathrm{O}$ direito das mulheres à autonomia decisória, como forma de garantia da sua integridade física e da proteção às identidades que lhes são caras (Cohen, 1997), é delimitado pela convergência entre formas de controle exercidas e normatizadas pelo Estado, pelo marido ou por homens que estão à frente de denominações religiosas. Mais uma vez, a gramática que justifica esse controle em nome da importância e santidade da reprodução e da maternidade não é distinta da gramática que justifica o direito dos homens ao corpo das mulheres, componente importante da tolerância social ao estupro e a outras formas de humilhação, violação e violência contra as mulheres. A valorização de formas convencionais da família, que é também uma peça-chave nessas posições, reduz a mulher ao papel de mãe, negando seu valor como indivíduo, o que mais uma vez colabora para justificar desigualdades e violência quando há "desvios".

As discussões aqui apresentadas também colaboram para uma análise crítica de como as teorias da política se situam em relação a essas diferentes dimensões do problema da autonomia e se, e de que forma, incorporam questões e aspectos das experiências dos indivíduos - e, mais especificamente, das 
mulheres - que são fundamentais para a construção de "uma posição plena e igual para todos os cidadãos, para que eles sejam igualmente respeitados e possam desfrutar do autogoverno, participando tão plenamente quanto o desejarem da vida social e política” (Pateman, 2009 [2002], p. 214). Nesse sentido, o debate sobre aborto se coloca no âmbito alargado do debate sobre "quais direitos são requeridos para minimizar a subordinação e maximizar a liberdade individual, e quais mecanismos são necessários para manter a sua efetividade" (Pateman, 2008, p. 241), enquanto permite ressaltar, por outro lado, os limites e filtros distintos e seletivos à autonomia individual segundo a posição - e, no caso, o sexo - dos indivíduos.

\section{Referências}

BADINTER, Elisabeth (1985 [1980]). O amor incerto: história do amor maternal do século XVII ao século XX. Lisboa: Relógio d’água.

BIROLI, Flávia (2013a). Autonomia e desigualdades de gênero: contribuições do feminismo para a crítica democrática. Niterói: Universidade Federal Fluminense; Vinhedo: Horizonte.

(2013b). "Democracia e tolerância à subordinação: livre-escolha e consentimento na teoria política feminista". Revista de Sociologia e Política, v. 21, n. 48, p. 127-42.

(2014). Família: novos conceitos. São Paulo: Fundação Perseu Abramo.

BOLTANSKI, Luc (2004). La condition foetale: une sociologie de l'engendrement et de l'avortement. Paris, Gallimard.

CLEMENT, Grace (1996). Care, autonomy, and justice: feminism and the ethic of care. Oxford: Westview Press.

COHEN, Jean L. (1997). "Rethinking privacy: autonomy, identity, and the abortion controversy”, em WEINTRAUB, Jeff \& KUMAR, Krishan (eds.). Public and private in thought and practice: perspectives on a grand dichotomy. Chicago: University of Chicago Press.

COLLOURIS, Daniella Georges (2010). A desconfiança em relação à palavra da vítima e o sentido da punição nos processos judiciais de estupro. Tese (Doutorado em Sociologia) - Faculdade de Letras, Filosofia e Ciências Humanas, Universidade de São Paulo, São Paulo.

CORNELL, Drucilla (1998). At the heart of freedom: feminism, sex, and equality. Princeton: Princeton University Press. 
CUNHA, Franklin (2007). O aborto e a liberdade. Disponível em: http:// www.providafamilia.org.br/site/secoes_detalhes.php?sc $=52 \& i d=48$. Acesso em: 12 jun. 2014.

DAVIS, Angela Y. (1983 [1981]). Women, race \& class. New York: Vintage. DEVEREUX, Georges (1955). A study of abortion in primitive societies. New York: International Universities Press.

DINIZ, Débora \& Marcelo MEDEIROS (2010). "Aborto no Brasil: uma pesquisa domiciliar com técnica de urna". Ciência \& Saúde Coletiva, $\mathrm{n}$. 15, p. 959-966.

DWORKIN, Ronald (2005 [2000]). Virtude soberana. São Paulo: Martins Fontes. (2009 [1993]). Domínio da vida: aborto, eutanásia e liberdades individuais. São Paulo, Martins Fontes.

ELSHTAIN, Jean Bethke (1981). Public man, private woman: women in social and political thought. Princeton: Princeton University Press.

FISCHER, John Martin (2003). "Abortion, autonomy, and control over one's body", em PAUL, Ellen Frankel; MILLER, Fred D. \& PAUL, Jeffrey. Autonomy. Cambridge, Cambridge University Press.

FOUCAULT, Michel (1999). Em defesa da sociedade: curso no Collège de France (1975-76). São Paulo: Martins Fontes.

FRIEDMAN, Marilyn (2003). Autonomy, gender, politics. New York: Oxford University Press.

GILLIGAN, Carol (1982). In a different voice: psychological theory and women's development. Cambridge: Harvard University Press.

HELD, Virginia (ed.) (1995). Justice and care: essential readings in feminist ethics. Oxford: Westview Press.

HOOKS, Bell (1984). Feminist theory: from margin to center. Boston; Brooklyn: South End Press.

HIGGINS, Jenny (2006). "Sex, unintended pregnancy, and poverty: one woman's evolution from 'choice' to 'reproductive justice", em JACOB, Krista (ed.). Abortion under attack: women on the challenges facing choice. Emervylle: Seal Press.

HTUN, Mala (2003). Sex and the State: abortion, divorce, and the family under Latin American dictatorships and democracies. Cambridge: Cambridge University Press.

KOHLBERG, Lawrence (1981). Essays on moral development: the philosophy of moral development. San Francisco: Harper \& Row. 
MACHADO, Maria das Dores Campos (2013). "Discursos pentecostais em torno do aborto e da homossexualidade na sociedade brasileira”. Cultura y Religion, v. 7, n. 2, p. 48-68.

MACKINNON, Catharine A. (1987). Feminism unmodified. Cambridge: Harvard University Press.

MIGUEL, Luis Felipe (2012). "Aborto e democracia”. Estudos Feministas, v. 3, n. 20 , p. 657-672.

\& BIROLI, Flávia (2014). Feminismo e política: uma introdução. São Paulo: Boitempo.

MILL, John Stuart (2008 [1859]). On liberty. Sioux Falls: New Vision Publications.

MINISTÉRIO DA SAÚDE (2009). 20 anos de pesquisas sobre aborto no Brasil. Brasília: Ministério da Saúde.

MOTTA, Flávia de Mattos (2012). "Não conta pra ninguém: o aborto segundo mulheres de uma comunidade popular urbana”, em AREND, Silvia Maria Fávero et al. (orgs.). Aborto e contracepção: histórias que ninguém conta. Florianópolis: Insular.

NUSSBAUM, Martha C. (1999). Sex and social justice. New York: Oxford University Press.

OKIN, Susan Moller (1989a). Justice, gender, and the family. New York: Basic Books.

(1989b). "Reason and Feeling in Thinking about Justice". Ethics, v. 99 , n. 2 , p. $229-249$.

(1999). "Is multiculturalism bad for women?", em COHEN, Joshua; HOWARD, Mathew \& NUSSBAUM, Martha (eds.). Is multiculturalism bad for women? Susan Moller Okin with respondents. Princeton: Princeton University Press.

PATEMAN, Carole (1985 [1979]). The problem of political obligation: a critique of liberal theory. Berkeley; Los Angeles: University of California Press. (1989). The disorder of women. Stanford: Stanford University Press. (2008). “Afterword”, em O’NEILL, Daniel; SHANLEY, Mary Lyndon \& YOUNG, Iris Marion (eds.). Illusion of consent: engaging with Carole Pateman. University Park: Pennsylvania State University Press. (2009 [2002]). "Soberania individual e propriedade na pessoa". Revista Brasileira de Ciência Política, n. 1, p. 171-218. 
PHILLIPS, Anne (2013). Our bodies, whose property?. Princeton and Oxford: Princeton University Press.

RAWLS, John (1971). A theory of justice. Cambridge: Harvard University Press.

RUDDICK, Sarah (1989). Maternal thinking: towards a politics of peace. Boston: Beacon Press.

SANTOS, Ivanaldo (s/d). Aborto, eugenia e neonazismo. Disponível em: http://www.providafamilia.org.br/site/_arquivos/2008/346__aborto_ eugenia_e_neonazismo.pdf. Acessado em: 5 mai. 2014.

SCHOEN, Johanna (2005). Choice and coercion: birth control, sterilization, and abortion in public health and welfare. Chapel Hill: University of North Carolina Press.

TAMAYO, Giulia (1999). Nada personal: reporte de Derechos Humanos sobre la aplicación de la anticoncepción quirúrgica en el Perú 1996-1998. Lima: CLADEM, 1999.

TAYLOR, Charles (1991). The ethics of authenticity. Cambridge: Harvard University Press.

(2005 [1994]). As fontes do self: a construção da identidade moderna. São Paulo: Loyola.

THOMSON, Judith Jarvis (1971). "A defense of abortion". Philosophy \& Public Affairs, v. 1, n. 1, p. 47-66.

YOUNG, Iris Marion (1990). Justice and the politics of difference. Princeton: Princeton University Press.

(1997). Intersecting voices: dilemmas of gender, political philosophy, and policy. Princeton: Princeton University Press.

\section{Resumo}

O artigo parte do entendimento de que existe um vínculo incontornável entre o direito ao aborto e o exercício da autonomia pelas mulheres para discutir elaborações distintas da relação entre autonomia e aborto no debate teórico e nos embates políticos. Apresenta, primeiramente, as linhas de força na argumentação liberal que dá sustentação ao direito ao aborto. Em seguida, expõe deslocamentos produzidos por abordagens feministas que ampliam ou tensionam os enquadramentos liberais. São exploradas, em especial, abordagens que criticam a compreensão restrita das escolhas, destacando o contexto em que se dão e suas implicações, e abordagens que fazem a crítica da noção liberal abstrata de indivíduo situadas no debate sobre "ética do cuidado". Por fim, equaciono brevemente o 
problema do sentido da vida ao da autonomia das mulheres. Argumento que as teorias feministas que extrapolam o liberalismo trazem contribuições ímpares ao debate sobre autonomia porque têm como ponto de partida as relações de gênero, dando centralidade às experiências das mulheres.

Palavras-chave: aborto, autonomia, igualdade, teoria política feminista, justiça.

\begin{abstract}
The article discusses different approaches to the connections between the right to abortion and the concept of autonomy. It starts froma brief presentation of the main axes in liberal arguments for the right to abortion. Then it discusses the displacements produced on those arguments by feminist approaches that either broaden or oppose liberal framings. At this point, the discussion underlines critical approaches to restricted comprehensions of choices, focusing on the contexts in which those choices take place and its implications. It also underlines feminist critics to the abstract notion of individual in liberalism, discussing their meanings and their limits in the debate about the "ethics of care". Finally, a brief conclusion brings together the value of autonomy and the meaning of life, redefined once feminist arguments based on women's experiences have been considered.
\end{abstract}

Keywords: abortion, autonomy, equality, feminist political theory, justice.

Recebido em 31 de maio de 2014.

Aprovado em 12 de agosto de 2014. 